\title{
Verifying 3G License Requirements
}

\author{
Some Preliminary Swedish Results
}

\author{
Claes Beckman \\ Center for RF-Measurement Technology \\ University of Gävle \\ Gävle, Sweden \\ cbn@hig.se
}

\author{
Elena Belkow, Lars Eklund, Urban Landmark \\ Post och Telestyrelsen \\ Stockholm, Sweden \\ Urban.landmark@pts.se
}

\author{
Per Wirdemark \\ Canaima Communications AB \\ Stockholm, Sweden \\ Per.wirdemark@canaima.se
}

\begin{abstract}
In the year 2000, the Swedish Telecom regulator "Post\& Telestyrelsen" (PTS) granted in a "beauty contest" four licenses for operation of $3 G$ mobile networks. Through this process, the licensees committed themselves to cover 8.860 .000 inhabitants of the Swedish population. In order to verify the coverage and confirm compliance with the license requirements, PTS, developed a test procedure in close collaboration with the licensees.
\end{abstract}

The present paper gives an overview of the considerations behind the design of the test method and presents some preliminary results. Today all Swedish $3 G$ operators comply with the licence requirement and it is concluded that a method for verifying the requirement accepted by the licensees is an important tool for successful licensing of spectrum and fulfilment of licensing obligations.

\section{$3 G$ networks; licence requirements, measurement method}

\section{INTRODUCTION}

In the year 2000, the Swedish Telecom regulator Post \& Telestyrelsen (PTS) granted four licenses for the operation of third generation mobile phone systems in Sweden through a beauty contest process. In acquiring the licenses, the licensees committed themselves to build networks that covered a population of 8.860 .000 inhabitants. This requirement implied that each operator would cover $99.98 \%$ of the Swedish population as counted vhen the licenses were given (and approximately $97 \%$ of the population of today). However, in order to support the roll out, the regulator allowed the operators to build their networks in a combination of self owned sites in the major cities (30\% of population) and shared sites in the countryside $(70 \%)[1]$.

Although the roll-out of these $3 \mathrm{G}$ networks was delayed several times and the coverage requirements somewhat modified, all operators reported in 2007 that they now comply with the coverage requirements. In comparison with other countries, Sweden is unique in that more than $98 \%$ of the population and $48 \%$ of the of the national territory (170.000 $\mathrm{km}^{2}$ ) has $3 \mathrm{G}$ coverage [2]

What are then the reasons behind this successful licensing effort? In contrast to many other European $3 \mathrm{G}$ licenses, the original Swedish definition of coverage specified a particular field strength measured outdoors on the primary common pilot channel, CPICH, that, supposedly, is related to a particular data service (rate) indoors.

When the license requirements were elaborated PTS had a view that the future $3 \mathrm{G}$-networks must support substantial higher performance than existing $2 \mathrm{G}$ networks. Thus, in the original license requirement the operators where obliged to provide a signal strength that corresponded to a downlink data rate services of $384 \mathrm{kbps}$ and an uplink service of $144 \mathrm{kbps}$, in doors. These requirements were then translated into a field strength for the signal received from the base station. The original coverage requirement was the following: When measured outdoors at a height of $1.7 \mathrm{~m}$ above ground over $5 \mathrm{MHz}$, the field strength on the CPICH should be at least 58 $\mathrm{dB} \mu \mathrm{V} / \mathrm{m}$ with an area probability of $95 \%$ [1].

To verify coverage PTS needed to develop a practical test procedure for measuring field strength, e.g. in a drive test [3]. However, designing such test presents a number of challenges:

- The requirement is given for a particular field strength measured on the common pilot channel, CPICH. However, the power to be allocated to the $\mathrm{CPICH}$ is not given by the regulator nor by base station manufacturer. In theory it is also possible to allocate anything between $0 \%$ and $100 \%$ of the available power to the CPICH. In practice the allocated power is almost always around $10 \%$ of the radio channel power [5];

- The license is given for covered area while a drive test only measures along a linear route. In order to convert 
measurement data from drive testing to a probability of coverage for a given area, one needs a statistical model based on population density and geography;

- There is no given relation between pilot power and services. The original license requirements set by PTS [1] assumed that a signal strength of $58 \mathrm{~dB} \mu \mathrm{V} / \mathrm{m}$ on the primary $\mathrm{CPICH}$ outdoors relates, in practise, to a downlink service of $384 \mathrm{kbps}$ and an uplink service of $144 \mathrm{kbps}$, indoors. However, building penetration path loss varies in different environment. Hence, field strength requirement should vary accordingly.

In order to solve these and other outstanding issues, PTS put together a working group with representatives from the licensees, the regulator and academia. The task of the working group was to come up with a test method and instrumentation that would be fair and acceptable to all parties.

The design of the actual measurement method is previously described in references [3-5] and will be only briefly described here. In this report we instead focus on the relevance of performing measurements on the $\mathrm{CPICH}$, statistical handling of the data and some initial results.

\section{PRIMARY COMMON PILOT CHANNEL}

The Universal Mobile Telephony System (UMTS) is a $3 \mathrm{G}$ systems specified by the Third Generation Partnership Project organization, 3GPP [6]. It has a radio interface based on a code division multiple access scheme, cdma, and $5 \mathrm{MHz}$ wide radio channels. Since the radio channel is somewhat wider than previous cdma systems it is referred to as: "wideband" cdma or WCDMA.

The primary Common Pilot Channel, $\mathrm{CPICH}$, is one of many codes in the WCDMA common downlink pilot channel. It is a control channel mainly used for handovers. It does not have a fixed power allocated to it so it is principle not related to any service in either the up- or down-link [6].

\section{A. Power allocation of $\mathrm{CPICH}$}

In theory it is possible to allocate anything between $0 \%$ and $100 \%$ of the available power to the CPICH. In practice the allocated power has a lower bound which can be derived as follows [7]:

In order to initiate a soft handover, a cell's pilot must be detected when an adjacent cell's pilot is $5 \mathrm{~dB}$ stronger. The required $\mathrm{E}_{\mathrm{b}} / \mathrm{N}_{0}$ on the primary $\mathrm{CPICH}$ on the downlink is approximately $10 \mathrm{~dB}$ [8]. The processing gain on the pilot is $10 * \log (3840 / 12.2)=25 \mathrm{~dB}$ which means the minimum output power for the pilot is approximately: $5+10-25=-10 \mathrm{~dB}$ $(10 \%)$ compared to the output power of the cells.

The operator can choose a higher value than $10 \%$ of the total power for the pilot. An increase in pilot power would also affect the license requirement in direct proportion. However, it is in the interest of the operators not to increase the pilot power unnecessarily since raising the pilot power will mean that less power is available for services and that the interference level is increased. Allocating between $5 \%$ and $20 \%$ of the available power in the radio channel is also often suggested in industry literature [7].

\section{B. Relationship between pilot power and services}

As described above, there is no given relation between pilot power and services. Still, in the license requirements set by PTS [1] it is assumed that a signal strength of $58 \mathrm{~dB} \mu \mathrm{V} / \mathrm{m}$ measured on the primary $\mathrm{CPICH}$ outdoors relates to a downlink service of $384 \mathrm{kbps}$ and an uplink service of $144 \mathrm{kbps}$, indoors.

In order to investigate whether or not these assumptions are true in all kinds of radio environments, Canaima Communications conducted an investigation on behalf of PTS [7]. Assuming that $10 \%$ of the available power is allocated to the primary $\mathrm{CPICH}$ and that building penetration path loss varies in different environments, it is now possible to estimate the pilot power needed to provide the above described services in different environments. The building penetration path loss was assumed to vary as:

- $\quad$ Dense Urban environment: 20dB;

- Urban environment: $16 \mathrm{~dB}$;

- Suburban environment $11 \mathrm{~dB}$;

- $\quad$ Rural environment $11 \mathrm{~dB}$;

TABLE I. LIMITING LINK AND REQUIRED CPICH SIGNAL STRENGTH

\begin{tabular}{|c|c|c|}
\hline Environment & $\begin{array}{c}\text { Limiting } \\
\text { Link }\end{array}$ & $\begin{array}{c}\text { Required CPICH } \\
{[\mathbf{d B} \boldsymbol{\mu} \mathbf{V} / \mathbf{m}]}\end{array}$ \\
\hline Dense Urban & UL & 65.1 \\
\hline rban & UL & 61.1 \\
\hline Suburban & UL & 56.1 \\
\hline Rural & UL & 54.6 \\
\hline Rural withTMA & UL & 49.6 \\
\hline
\end{tabular}

A first problem to resolve is to determine whether it is the up- or the down-link that sets the limit for the service? The results from [7] are summarized in Table I. In all environments studied it is the up-link that limits the service performance. However, the license requirement of $58 \mathrm{dBmV} / \mathrm{m}$ seems to be set approximately $7 \mathrm{~dB}$ too low in dense urban environments and $\sim 8 \mathrm{~dB}$ too strict in rural environments, assuming that the operators are using Tower Mounted Amplifiers, TMA, and that $10 \%$ of the available radio power has been allocated to the pilot channel.

TABLE II. MODIFIED COVERAGE REQUIREMENT

\begin{tabular}{|c|c|}
\hline Environment & $\begin{array}{c}\text { Required CPICH } \\
{[\mathbf{d B} \boldsymbol{\mu} \mathbf{V} / \mathbf{m}]}\end{array}$ \\
\hline Dense Urban & 58 \\
\hline Urban & 58 \\
\hline Suburban & 54 \\
\hline Rural & 54 \\
\hline Rural withTMA & 50 \\
\hline
\end{tabular}

The conclusion from [7] made PTS change their $\mathrm{CPICH}$ field strength requirement retroactively. The result is given in 
Table II and is the basis for the current license requirements and the definition of coverage as verified in this report.

\section{STATISTICAL MODEL}

The purpose of the test method is to establish whether or not an operator has fulfilled the coverage requirements set out in the license [3]. The method must ensure that the license requirement is fulfilled with sufficient statistical significance and that the sampled data is uncorrelated.

The method chosen to ensure that the data is uncorrelated is to make sure it is received over a large enough geographical area. This is done by dividing the geographical area to be verified for 3G coverage into "test squares". If $95 \%$ of the tested squares have a sampled field strength exceeding the one set out in the license requirement, the area is considered to be covered.

\section{A. $\quad$ Test squares}

The size of the test squares is dependent on the environment and population (Table II and Figure 1). The denser the population the smaller the size. In the evaluation only one sample for each test square is used.

TABLE III. SIZE AND POPULATION OF TEST SQUARES

\begin{tabular}{|l|c|c|}
\hline \multicolumn{1}{|c|}{ Environment } & Population (per square) & Size (m) \\
\hline Rural & $0<=\mathrm{x}<20$ & 500 \\
\hline Suburban & $20<=\mathrm{x}<80$ & 250 \\
\hline urban & $80<=\mathrm{x}<200$ & 125 \\
\hline Dense Urban & $\mathrm{x}>=200$ & 50 \\
\hline
\end{tabular}

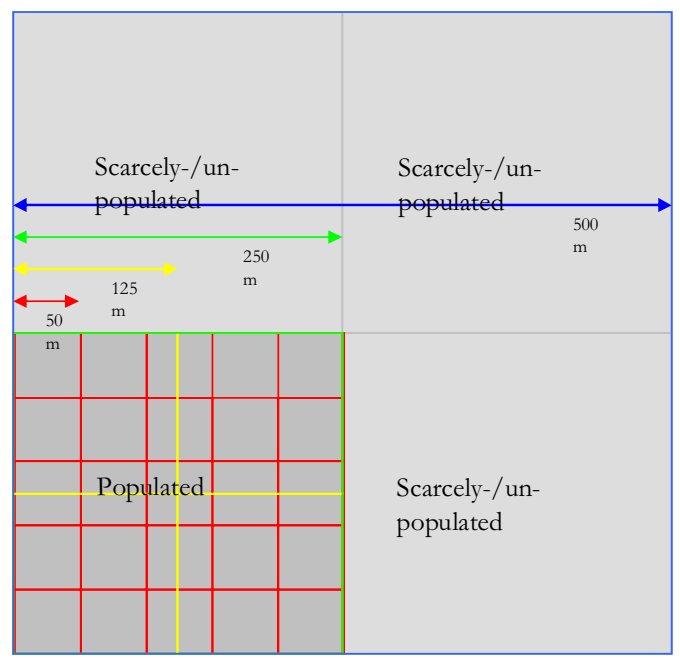

Figure 1. Size relation between test squares

For practical reasons the measurements are conducted in a drive test using a car. Hence the sampling rate is dependent on the speed of the car and the size of the test squares. Each tested square is allocated the value of " 1 " if the license requirement is fulfilled and "0" if not. At least 500 test squares are measured in order to assume that the number of "1" are binomially distributed $(n ; p)$ where $p>=0.95$ in the event that the license requirements are fulfilled.

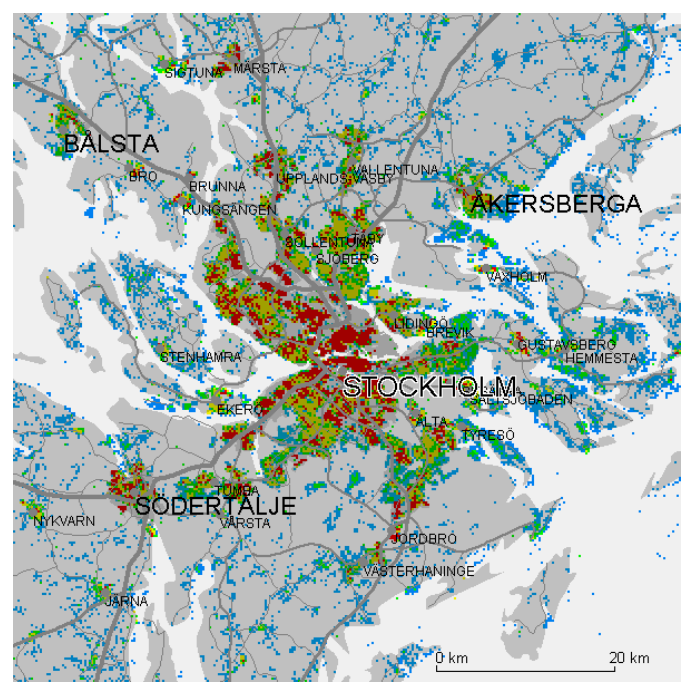

Figure 2. Graphic illustration of the population density in the Stockholm area (including Sundbyberg)

\section{PRELIMINARY RESUlTS}

In 2007 all licensees reported that they have now fulfilled the modified coverage requirements [2]. In order to verify these claims PTS subsequently conducted some initial and preliminary tests.

\section{A. Test case Fagersta: suburban environmnent}

The first test case was conducted in a typical Swedish suburban environment in an area of the city of Fagersta. In total 535 test squares were measured and in order to pass the test not more than 39 were allowed to fail for the operator to be deemed in compliance with the license requirement.

As shown in Table IV, the result from the operator presented here passes the test easily. Even if the CPICH field strength requirement would be increased to $53 \mathrm{~dB} \mu \mathrm{V} / \mathrm{m}$ would the operator still pass the test indicating that the planning is fairly robust against fading.

TABLE IV. TEST RESULTS FROM FAGERSTA

\begin{tabular}{|c|c|}
\hline $\begin{array}{c}\text { Field strength requirement } \\
(\mathbf{d B} \boldsymbol{\mu} \mathbf{V} / \mathbf{m})\end{array}$ & No. Failed Squares \\
\hline 53 & 31 \\
\hline 52 & 23 \\
\hline 51 & 19 \\
\hline 50 & 17 \\
\hline 49 & 16 \\
\hline 48 & 9 \\
\hline 47 & 6 \\
\hline
\end{tabular}

\section{B. Test case Sundbyberg: urban environment}

The second test was conducted in a typical Swedish urban environment in the city of Sundbyberg some $10 \mathrm{~km}$ north of 
Stockholm. In total 602 test squares were measured and in order to pass the test not more than 43 could fail for the operator to comply with the license requirement. In this environment the required field strength on the $\mathrm{CPICH}$ is $58 \mathrm{~dB} \mu \mathrm{V} / \mathrm{m}$.

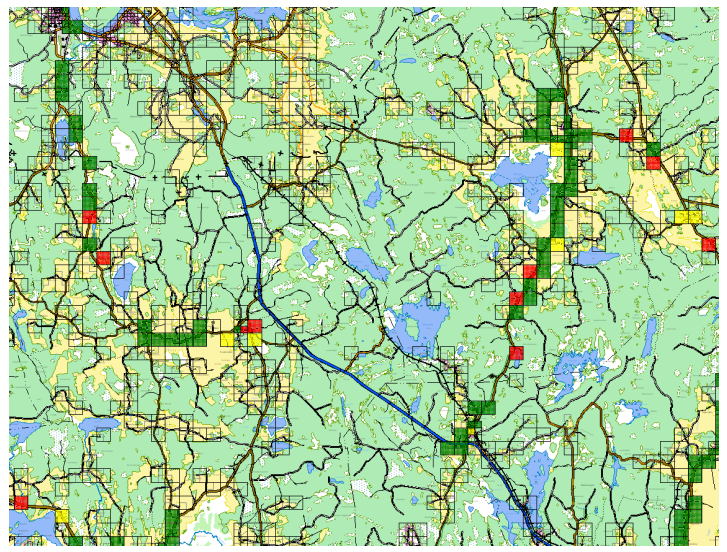

Figure 3. Graphic illustration of coverage in the Fagersta region at the $50 \mathrm{~dB} \mu \mathrm{V} / \mathrm{m} \mathrm{CPICH}$ level. Green Squares indicate Test squares passed, yellow are at the boarder line, and red square are failed.

TABLE V. TEST RESULTS FROM SUNDBYBERG

\begin{tabular}{|c|c|}
\hline $\begin{array}{c}\text { Field strength requirement } \\
(\mathbf{d B} \boldsymbol{\mu} \mathbf{V} / \mathbf{m})\end{array}$ & No. Failed Squares \\
\hline 64 & 11 \\
\hline 63 & 9 \\
\hline 62 & 5 \\
\hline 61 & 3 \\
\hline 60 & 1 \\
\hline 59 & 0 \\
\hline 58 & 0 \\
\hline 57 & 0 \\
\hline
\end{tabular}

As is evident from Table $\mathrm{V}$, the coverage planning is even more robust and the field strength on the $\mathrm{CPICH}$ higher in urban areas. Even if the requirement is increased with $6 \mathrm{~dB}$ the result for the examined operator is still clearly above the limit of $95 \%$ area coverage

\section{V. . DISCUSSIONS AND CONCLUSIONS}

In the beginning of this century $3 \mathrm{G}$ was introduced and most countries in the western world allocated spectrum for this technology through some kind of procedure. In Europe, the prevailing approach was to allocate spectrum through auctions, a process which led to devastating consequences in which operators found themselves committed to paying a staggering 130Bilion Euros for these licenses. Seven years later, many markets are still suffering the consequences of these events in the form of limited coverage and low penetration of $3 \mathrm{G}-$ based services throughout much of Europe

In Sweden the 3G licenses were awarded after a beauty contest, in which the winners committed themselves to cover a population of 8.886 .000 which at the time corresponded to $99.98 \%$ of the country's population. Although the requirements were later substantially eased, it remains true that no other country in the world approaches the standards Sweden has set for $3 \mathrm{G}$ coverage and service deployment [2].

An important factor may have been that the license requirements in Sweden were concrete and measurable. The fact that PTS developed a method to verify the implementation that was accepted by all licensees in combination with equipment for practical tests, we believe has been another factor that facilitated the roll-out, as ambiguity concerning how to interpret vague service requirements was minimized and the ability for PTS verify the requirements real.

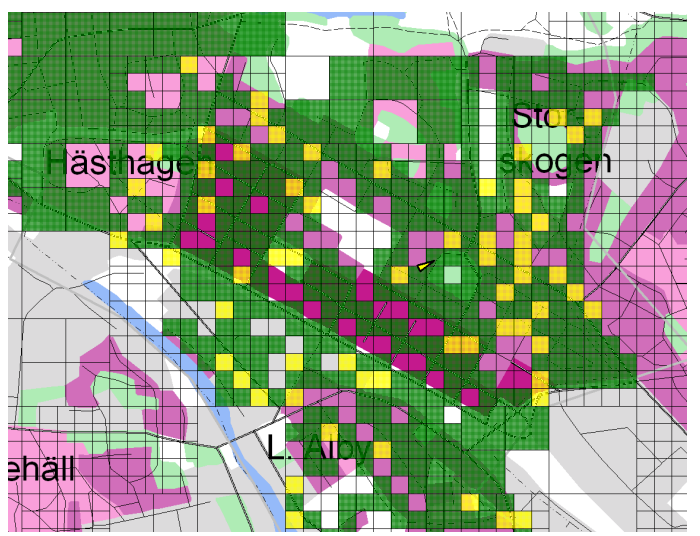

Figure 4. Graphic illustration of coverage in the Sundyberg region at the $58 \mathrm{~dB} \mu \mathrm{V} / \mathrm{m}$ CPICH level. Green Squares indicate Test squares passed, yellow are at the boarder line, and red square are failed.

\section{ACKNOWLEDGMENT}

The Authors would like to thank the participants of the $3 \mathrm{G}$ test method working group who all contributed in the development of the test. We would also like to acknowledge constructive comments on the manuscript by Mr. Gregory Smith.

\section{REFERENCES}

[1] "Meddelande av tillståndsvilkor för nätkapacitet för mobila teletjänster av UMTS/IMT-2000 standard enligt $15 \S$ telelagen (1993:597)", HK 017950, The Swedish National Post and Telecom Agency, PTS March 2001

[2] "Dimensionering och kostnad för utbyggnad av UMTS", The Swedish National Post and Telecom Agency, PTS, Report To be published September 2008.

[3] "Method för uppfölkjning av tillståndsvilkoren för UMTS-näten", The Swedish National Post and Telecom Agency, PTS, Report Number PTSER-2004:23. June 2004.

[4] D. Ribbenfjärd, B. Lindmark, B. Karlsson, and L. Eklund, "Omnidirectional Vehicle Antenna for Measurementof Radio Coverage at 2 GHz", IEEE Antennas and Wireless Propagat. Letter, VOL. 3, 269272,2004

[5] C. Beckman, B. Lindmark, B. Karlsson, L. Eklund D. Ribbenfjärd and P Wirdemark, " Verifying $3 \mathrm{G}$ licence requirements when every $\mathrm{dB}$ is worth a bilion ", European Conference on Antennas \& Propagation: EuCAP 2006

[6] 3rd Generation Partnership Project Technical Specification Group Radio Access Networks: "BS Radio transmission and Reception (FDD)", 3GPP TS 25.104 V4.8.0, September 2005.

[7] P. Wirdemark, "Coverage Requirements for UMTS", The Swedish National Post and Telecom Agency, PTS, Report Number PTS-ER2004:32. September 20 